\title{
Grieehiseh-Orientalisehe Untersuchungen.
}

\author{
Von C. Fries.
}

\section{Homerische Beitriige.}

\section{Einleitung.}

Als vor hundert Jahren etwa die homerische Frage alle Gelehrten und Gebildeten beschäftigte, da vermeinte man, mitleidig auf die gesamte frühere Wissenschaft herabsehen zu können, die in ihrem Homer den grossen Künstler und Dichter verehrt und über seine Lebensumstände nachgedacht hatte. Jetzt sah man in ihm den "Günstling seiner Zeit", die Persönlichkeit verflüchtigte sich gä口zlich und eine Schar von Sängern trat an ihre Stelle. Die grösste Errungenschaft aber war, dass man für die damals bevorzugte Volksdichtung in den griechischen Heldengesängen neue Beispiele gewonnen hatte.

Seitdem weiss man vieles besser. Von dem naiven Volkssänger ist nicht viel übrig geblieben. Vielmehr erscheinen uns die Verfasser der homerischen Epen jetzt in enger Verbindung mit dem mächtigen, bei den Fürsten einflussreichen Priestertum; und mit dem Sinken der weltlichen Wächte versinkt auch ihr Stern, sie werden wieder zu Bänkelsängern und Parasiten. ${ }^{1}$ ) Wir haben ja im ausgehenden Vittelalter ganz ähnliche Erscheinungen. In so vielen Dingen zum Umlernen gezwungen, haben wir die Gläubigkeit früherer Geschlechter, mit der sie jede Eigentümlichkeit, jede Laune homerischen Stils als volkstümliches Erbgut dunkler Überlieferungen hinnahmen, eingebüsst und fragen nach Quellen! Man hat wohl innerhalb der epischen Sphäre nach Entwickelungen und Fortbildungen geforscht, sah sich aber schliesslich doch immer im Kreise berumgeführt. Nun trat eine alte orientalische Litteratur viel höheren Alters ans Licht, der ganze Lehrgebäudé aufgeopfert werden mussten. Die Welt Babels tauchte aus der Vergessenheit vieler Jahrtausende auf. Nach allen Seiten ergingen Strahlen frischer Anregung und Belebung. Nichts lag näher, als nun auch die homerische Frage dieser neuen Belenchtung auszusetzen und zu erproben, wie sie auf diese noch unversuchte Einwirkung reagieren werde. P. JENSEN in Marburg trat mit kühnen Thesen in der Zeitschrift für Assyriologie ${ }^{2}$ ) hervor und wurde zu-

1) Vgl. Rhein. Mus. 57, 269. - 2) 1902 S. $125 \mathrm{ff} ., 413 \mathrm{f}$. 
nächst von den klassischen Philologen in gralsamster Weise abgefertigt. Nicht in den Einzelheiten, die sie bemängelte, hatte diese Kritik Unrecht. Das Verdienst der Genauigkeit in Einzelheiten wird ihr gewiss niemand bestreiten, obgleich auch da wohl nicht alles in Ordnung war. Unrecht hatte sie vor allem aber in dem Standpunkt, den sie der neuen Anregung gegenüber einnahm. Wo sie nachsichtig hätte entgegenkommen, wo sie durch thätiges, helfendes Eingreifen unendlichen Nutzen hätte stiften sollen und können, da verdarb sie durch ihr abweisendes Verhalten alles, erregte Bitterkeit und hätte den zarten Keim eines neuen, wichtigen Forschungsgebietes fast erfrieren lassen, wenn dessen Triebkraft nicht allzu stark wäre. ${ }^{1}$ ) Es gilt nun, die homerische Frage weiter zu behandeln, aber mit neuem Rüstzeug. Je mehr man sich dabei von Phantastik und kühner Konjektur frei hält, um so besser für die Sache. So rücksichtslos wie möglich muss bei Seite geschoben werden, was nicht für sich selbst spricht, vom Kleinen soll ausgegangen, weitgreifende Hypothesen sollen zunächst vermieden werden.

Nicht aber ist es darauf abgesehen, das Problem selbst aus der Welt zu schaffen. Dass von Babylon und Memphis Einwirkungen nach Hellas ausgingen, das leugnen selbst die entschiedensten Gegner der Beeinflussungstheorie nicht ab. Nur darf man, wie gesagt, nicht grosse Eroberungszüge ins Werk setzen, wo sorgfältigste Kleinarbeit allein zum Ziel führen kann. $\left.{ }^{2}\right)$

Im Folgenden soll besonders von Homer die Rede sein, gelegentlich wird auch auf andere ältere griechische Dichter hinübergegriffen, im Ganzen aber handelt es sich hier um Beiträge zur Litteratur des homerischen Zeitalters, und in diesem Sinne möchte obiger Titel aufgefasst werden.

Es gilt, nachzuprüfen, ob zwischen der homerischen Kunstweise und den Bruchstiucken babylonischer Epen irgendwelche Ähnlichkeiten bestehen, nicht aber, wie man befürchten könnte, ist es auf Identifikationen im Grossen abgesehen, die zu nichts führen, im Gegenteil sollen Einzelzüge, besondere Ausdrucksformen, Eigentümlichkeiten des epischen Stils verglichen werden; nur ein solches Verfahren dürfte für methodisch erachtet werden, und nur wenn hier eine gewisse Basis gewonnen ist, kann man zu etwas kühneren Flügen in das Gebiet des Mythos ausholen, freilich auch zu keinen ikarischen Aufstiegen, sondern zu solchen, bei denen der feste Boden der Wirklichkeit stets im Auge behalten wird. Das Streben,

1) Hätte $J_{\text {ENSEN }}$ auch nur das Verdienst, die Frage in Fluss gebracht zu haben, so wäre dieses schon sehr gross. Hoffentlich erfullt er aber bald seine Zusage, die vorausgeschickten Thesen auf breiterer Grundlage zu erhürten! Man muss diesem Werk mit grösster Spannung entgegensehen.

2) Vgl. auch C. F. Lemmann, Beitr. z. alten Geschichte II 341 Anm. 
jenes zu vermeiden, liegt in dieser Arbeit überall vor, wie weit es erreicht worden ist, darüber möge die Kritik entscheiden.

Es soll also zunächst von stilistischen Eigentümlichkeiten die Rede sein und hierbei wird sich allerdings einiges Übereinstimmende in griechischer und babylonischer Epik ergeben. Dann wird zu einzelnen Motiven der epischen Erzählung iibergegangen und zuletzt in einem besonderen Abschnitt sollen zwei Episoden der homerischen Gedichte, die Kyklopeia und die Doloneia, einer eingehenderen Betrachtung unterzogen werden.

Zum Sehluss sei das Unterfangen des Nichtorientalisten, iiber Orientalia das Wort zu ergreifen, der Nachsicht derjenigen empfohlen, denen der Vers: „Denn es ist Drang, und so ist's Pflicht" auch auf wissenschaftlichem Gebiet einige Geltung hat. Ermutigend wirkte u. a. das grosse Beispiel Hermann Useners, dem es ja vergïnnt war, vom Heimatboden der griechischen Studien aus erfolgreiche Züge in die orientalischen Grenzgebiete zu unternehmen.

A. Zur Geschichte des epischen Stils und einiger homerischer Motive.

Der beleidigte Achilleus ruft nach der Abholung der Briseis die Mutter an und erzählt ganz kurz, was ihm widerfahren: „Der Atreide lat mich beschimpft, er lat mir mein Ehrengeschenk fortgenommen." Thetis entsteigt ihrem Element und fragt den Sohn: "Weshalb weinst Du? Welcher Schmerz traf Dich? Sprich, verbirg es mir nicht, damit wir beide darum wissen." Er aber erwidert: "Du weisst es ja! Was

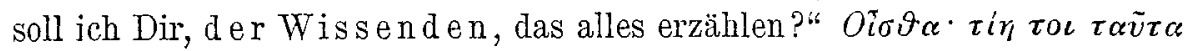

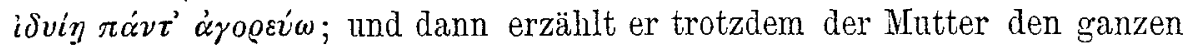
Hergang bis in das Einzelste noch einmal ganz genau ( $A$ 366-392). Aristarce hat die Erzählung athetiert, unter den Neueren folgte ihm

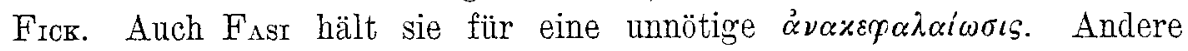
meinen, die erregte Stimmung des Achill erkläre seinen Wortreichtum und seine Inkonsequenz (s. Ameis-Hentze z. d. St.). Aus sich heraus lässt sich die Stelle nicht verstehen und beurteilen, man muss eine ähnliche heranziehen, nämlich diejenige, an der Menelaos von seinem ägyptischen

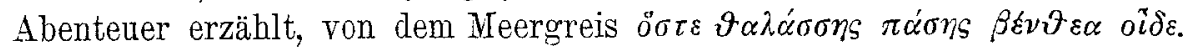
Er könne, meint Eidothea, über alles Nachricht geben, was daheim Gutes oder Übles sich ereignet habe, seit Menelaos die lange unheilvolle Fahrt angetreten. Menelaos zwingt den Proteus, ihm in seiner wahren Gestalt entgegenzutreten. Dieser fragt erstaunt: „Wer lehrte dich das Geheimnis, mich zu fangen? Was ist dein Begehr?" Nenelaos aber lässt sich nicht beirren: „Du weisst es, wie ich hier zurückgehalten werde und nicht

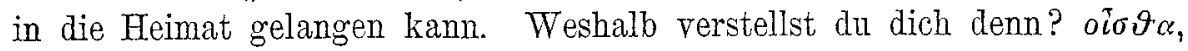

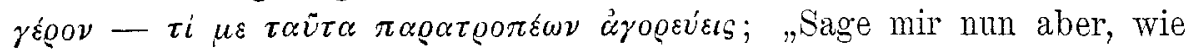
ich die Heimfahrt bewerkstelligen soll, denn die Gütter sind ja allwissend." 


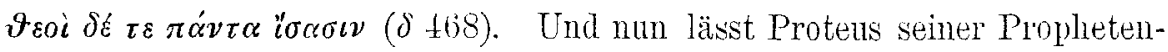
gabe freien Lauf. Der Odysseedichter ist gewitzigter als der Sänger der

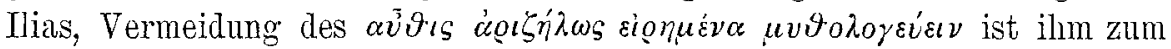
festen Grundsatz geworden. Die Götter sind ja nach homerischer Anschaumg allwissend, und doch bringt es der Verlauf der Handlung mit sich, dass sie gelegentlich recht unwissend erscheinen. $\Sigma 185$ merkt Zeus nicht, dass Hera heimlich die Iris zum Achill geschickt hat. Hera weiss $A 540$ nichts von den Entschliessungen ihres Gemahls. Ares verliert seinen Soln Askalaphos in der Schlacht, olne selbst davon Kenntnis zu erlangen. ( $N$ 518). Erst $O 110$ verrät es ihm Hera, und er bricht nun augenblicks auf, um den Sohn zu rächen. NageLsbacu zähllt') 7 Fälle dieser Art in der Ilias, in der ein ganzer Gesang danach benannt ist (Aios ả áx $\tau \eta$ ), nnd 4 in der Odyssee. Der Iliasdichter war eben der naivere, und in diesem Sinn ist anch jene Umständlichkeit $A 365$ aufzufassen. Die Verse ans diesem Grunde zu streichen, wäre verkehrt. $\omega 471 \mathrm{ff}$. fragt Athene ihren Vater, ob er in Ithaka num Frieden oder Krieg walten lassen wolle. Zeus antwortet ihr:

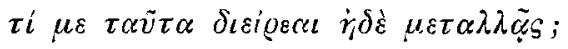

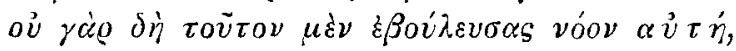

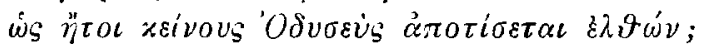

Nun erzählt eine babylonische Thontafel²), wie ein Mensch von einem Dümon befallen wurde und wie er nnter der Gewalt des Fluches dahinsiecht. Marduk erblickt ihn, er geht zu seinem Vater Ea und erzählt ilım, was jenem Sterblichen widerfahren. „Zum zweitenmal erzählte er es ihm" $(27,24)$, wobei unter dem ersten Male der eigene Bericht des Schreibers oder Priesters zu verstehen ist. Marduk möchte nun erfahren, wie seinem Schützling zu helfen sei. Der Vater des Gottes antwortet diesem: „Mein Sohn! Was wüsstest du nicht, was könnte ich dir noch mehr sagen; Marduk! was wüsstest du nicht, was könnteichdirnoch weitersagen? Wasich weiss, das weisst a uch du." Dann aber setzt er seinem Sohn in ausgedehntester Weise die Schritte auseinander, die zur Lösung des Bannes zu thun sind. Es liegt also dasselbe vor, wie in der Ilias. Auf einer anderen Tafel wird beschrieben, wie ein Gott aus der Tiefe gestiegen ist und böse Geister Schrecken über die Erde verbreiten und alle Menschen peinigen. Besonders einen Unglücklichen erkoren sie sich und plagten ihn mit Leiden und Krankheiten verschiedenster Art. Auch ihn erblickt Marduk, auch hier befragt er seinen Vater Ea: „Nicht weiss ich, was jener Mensch begangen und wodurch er genesen wird" $(39,44)$. Ea antwortet wört-

1) Homerische Theologie 23. Anmerkungen zur Ilias ${ }^{3} 135$.

2) Beitrage zur Kenntnis der babylonischen Religion v. H. Zаманам, Die Beschworungstafeln Šrupu. Leipzig 1901 S. 27. 
lich dasselbe, wie in der elsteren Tafel, jener wüsste alles, was auch er wisse, dennoch setzt er ihm auch die zur Erlösung jenes Mannes erforderlichen Massnahmen auseinander. Hierher gehört auch eine Stelle der Snorra Edda. Im Gylfaginnîng heisst es: „Er (Thôr) fragte ihn (den Riesen) aber nach seinem Namen und er nannte sich Skrymir. Und nichtbraucheich, sagte er, dich um deinen Namen zu fragen: ich weiss, dass du Asathor bist." ${ }^{1}$ ) Es wäre nicht undenkbar, dass jene Formel mit so manchem anderen sich über Kleinasien nach Jonien fortgepflanzt hätte. Sie hat übrigens eine bestimmte Bedeutung. Es hätte den Gott herabgesetzt, wenn er etwas nicht wüsste. Das Wiss en, besonders in sakralen Dingen, galt für ausserordentlich wesentlich. Der Gott darf nie unwissend erscheinen. Geflissentlich hebt der Sänger des $\varepsilon$ hervor, dass Kalypso den nahenden Hermes sofort erkenne, ở yáo $\tau^{\prime}$

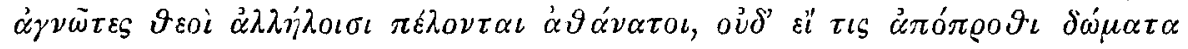
vaisı. Weiteres s. u.

Im ersten Gesang der Mias, unweit der oben berührten Stelle, schwört der beleidigte Achill bei seinem Scepter, nie wieder den Achaiern zu helfen. „Bei diesem Scepter, das keine Blätter und Zweige mehr tragen wird, nachdem es im Gebirge vom Stamm geschnitten ward, das nie wieder erblühen wird, denn die Axt schälte ihm Bast und Blätter $a b$, nun tragen es aber die Söhne der Achaier in Händen, wenn sie des Rechtes walten vor Zeus, - einst werdet ihr des Achilleus gedenken" u. s. w. Den Schwur begleitet er mit einer symbolischen Handlung, er wirft das Scepter zur Erde, nun liegt es am Boden, ein Sinnbild des Unveränderlichen, nie mehr Fruchttragenden, des Unbelebten. Der Schwur beim Scepter findet sich auch $H 412$ und $K$ 328. - Kehren wir nun zu jener Beschwörungstafel zurück und sehen die Antwort an, die Ea seinem Sohne erteilt, um den vom Dämon befallenen Menschen zu heilen. „Der Bann werde durch die Beschwörung Eas wie eine Zwiebel abgeschält, wie eine Dattel abgeschnitten" etc. (29, 50 ff.). Nun ergreift der Gebannte selbst das Wort, während er die angedeuteten symbolischen Handlungen gleichzeitig vollzieht. "Wie diese Zwiebel abgeschält und ins Feuer geworfén wird, die lodernde Flamme sie verzehrt, wie sie in ein Beet nicht mehr gepflanzt, mit Furche und Gräbchen nicht mehr umzogen wird, im Boden nicht mehr Wurzel schlägt, ihre Röhre nicht mehr wächst, das Sonnenlicht nicht mehr erblickt, wie sie auf den Tisch eines Gottes oder Königs nicht mehr kommt, so werde der Fluch, der Bann — - wie diese Zwiebel abgeschält! Heutigen Tages verzehre sie die lodernde Flamme! Der Bann weiche, ich aber möge Licht schauen." (cf. Aesch. Ag. ä̈ $\iota \nu o \nu$

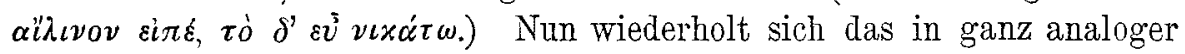
Weise mit immer abwechselnden Symbolen noch sechsmal, immer wieder

1) S. HAUPTS Zeitschr. f. deutsches Altert. VII 31. 
zeigt sich dieselbe Gedankenfolge. Wie die Dattel auf den leeren Zweig nicht mehr zurückkehrt, wie die Palmenrispe zur Palme nicht zurückkehrt, zu ihrer Ausschmückung nicht mehr taugt, wie das Schaffell zum Schaf nicht zurückkehrt, zu einem Kleid nicht mehr gebraucht wird, ebenso das Ziegenfell, wie aus dieser Wolle der Weber kein Gewand mehr weben wird, wie diesen Samen der Landmann auf dem Felde nicht mehr aussät, wie er nicht mehr keimt, die Sonne nicht mehr erblickt - - "." Bei dem Babylonier wird das Symbol vernichtet, bei Homer das schon entseelte simnbildich gleichsam zu nochmaliger Vernichtung zu Boden geworfen, bei beiden wird ausgemalt, welche Funktionen das Symbol nicht mehr ausiiben wird. Man ist versucht zu glauben, dass diese Schwurformel sich aus der genannten Beschwörungsformel entwickelt hat. Man könnte sich den Übergang etwa so vorstellen: Bei der Beschwörung autorisiert der Gott zunächst den Priester, die Lösung des Bannes zu veranstalten, der Priester teilt die Absicht des Gottes mit, nun tritt der Gebannte selbst ein und vollzieht mit symbolischen Handlungen den Willen des Gottes, er wird zum ausführenden Beamten des letzteren. Bei jenem Schwur fehlt die Autorisation des Gottes, der Schwörende erklärt aus eigner Wachtvollkommenheit, oft freilich mit Anrufung des Gottes, dass dies und das geschehen werde, so gewiss, wie - - etc. Der Gebannte hat die Genehmigung der Götter eingeholt und erlangt und gehorcht nur noch ihrem Willen, der Schwörende ruft die Götter oder Naturgewalten nur noch als Zeugen an. Das einzige Verhältnis, das er zu ihnen hat, ist das der Wahrheit und Aufrichtigkeit, bei ihnen falsch zu schwören, bringt ihm Verderben. Dort ist der Gott der aktive Teil, hier der Mensch. Diese Art des Schwurs beruht also offenbar ursprünglich auf einer lustralen Handlung, die Rolle des Gottes aber hat der Mensch selbst übernommen. Ähnliche Züge derartiger Gelïbde finden sich in zahlreichen Sagen und Legenden aller Völker, das Wunder tritt hinzu, verdorrte Zweige begrïnen sich wieder, die Mirakelpoesie ward ja von der Kirche mit Liebe gehegt. Alles das mag in der Symbolik derartiger lustraler Handlungen seine letzte Erklärung finden. An den realen Kern, dass das vernichtete Symbol nie wieder anfleben werde, rankte die Phantasie das Wunder an von dem Aufblühen und Grünen des verdorrten Stabes.

C. F. Lehmans berichtet von einem noch jetzt in Armenien bestehenden Baumkultus ${ }^{2}$ ) und erzählt dabei von einem so verehrten Baume

1) Vgl.: „Wie dieser Bock nicht zur Heerde zurückkehrt", Perser, Mitteilung der Vorderasiat. Ges. 1898 S. 229.

2) Archiv für Religionswissenschaft IIX $11 \mathrm{ff}$. Aus Georgien, in der „Zeit" 1902 No. 41. Für Achills Schwur u. a. vgl. jetzt auch R. HrazeL, Der Eid (Lpz. 1902) 215, 3. H. hat die babylonischen Parallelen ganz ubersehen, sie werfen gerade auf dies Gebiet neues Licht. 
folgende Sage: „Ein Bischof habe ein weltliches Leben geführt und als er gestorben, habe man eine Eiche verkehrt, mit der Krone nach unten, eing'epflanzt. Wenn der Baum weiter wüchse, so komme der Bischof in den Himmel, sonst nicht. Der Baum sei gewachsen". Ähnliches findet sich in einer böhmischen Sage, die man bei HERDER in den Volksliedern findet ("Die Fürstentafel"). Die Sage von Meleager hängt mit diesen Vorstellungen zusammen. Solang der Strauch nicht ins Feuer geworfen wird, darf er leben, sobald Althaia ihn aber auf den Herd wirft, stirbt ihr Sohn. Der alte Ritus lebt als ausgebildeter Hythos fort und ist nicht zum Gleichnis, zum Symbol abgeblasst. Besonders deutliche Parallelen zu der babylonischen Beschwörung aber bietet Indien. In den Zaubersprüchen des Atharvaveda findet sich manches Entsprechende. Ganz ähnlich wird dem buddhistischen Novizen eingeschärft, sich vor den vier Hauptsünden zu hüten. ${ }^{1}$ ) Da heisst es dann: „Wie jemand, dessen Haupt vom Rumpf getrennt ist, nicht leben kann, ebensowenig kann ein Mönch, der diese Hauptsünde begangen hat, ein Asket, ein Çâkyasoln sein. - Wie ein verwelktes Blatt, das, vom Stengel gerissen, nicht wieder grün werden kann, ebensowenig kann ein Mönch u. s. w. - Wie ein in zwei Teile gespaltener Felsblock nicht wieder ganz gemacht werden kann, ebensowenig kann ein Mönch u. s. w. - Wie ein seiner Krone beraubter Palmbaum nicht wieder ausschlagen kann, ebenso ...". Die Ähnlichkeit erstreckt sich z. T. sogar auf die Vergleichsobjekte selbst:), sodass an einem historischen Zusammenhang wohl kein Zweifel sein kann.

Hier muss ich noch einige weitere Entsprechungen aus der buddhistischen Litteratur erwähnen. - „Solcher Wahn ist vom Vollendeten aus der Wurzel abgeschnitten, einem Palmstumpf gleichgemacht, ausgerodetworden, kann sich ferner nicht mehr entwickeln " (Majjhimanikāyo, Jivako p. 370 Trenckner. K. E. Neumann, Reden Gotamo Buddhos II S. 50.) - „Gleich wie etwa - eine Palme, der man die Krone abgeschnitten hat, nicht wieder emporwachsen kann, ebenso auch - hat der Vollendete den Wahn - überstanden, an der Wurzel abgeschnitten, einem Palmstumpf gleichgemacht, sodass er nicht mehr keimen, nicht mehr sich entwickeln kann." (Nalakapānam 464. Neumann II 204). — "Jede Unterscheidung - ist vom Vollendeten überstanden, an der Wurzel gleichgemacht worden, sodass sie nicht mehr keimen, nicht mehrsich entwickeln kann" (Vacchagotto 2 p. 488, Neumann II 244). Wenige Zeilen darauf dieselbe Formel. "Wenn da nun ein Mönch die Lebenslust verleugnet, an der Wurzel abgeschnitten, einem Palmstumpf gleichgemacht lat, sodass sie nicht mehr keimen,

1) Kerro $\mathrm{J}_{\mathrm{ACORI}}$ Der Buddhismus II 40 f. - 2) Vgl. auch Ot.Denderg, Budtha 401. 
nicht mehr sich entwickeln kann, dann ist er ein heiliger Mönch" (Vacchagotto 3 p. 490, Neumann II p. 247) u. a. Der Anklang an die babylonische Beschwörung ist deutlich: "Wie die Palmenrispe zur Palme nicht zurückkehrt, zu ihrer Ausschmückung nicht mehr ta ugt - - (s. o.). Das Bedeutsamste ist, dass altbabylonische'Zauberformeln in buddhistischer Dialektik als ständiges Mittel philos oph is cher Beweisfïhrung und ethisch-dogmatischer Spekulation erscheinen, bedeutsam für die Entwicklung des philosophischen Denkens überha upt! Das Beharren solcher Motive zeigt, wie gewaltig der Eindruck anf Phantasie und Gemüt einst gewesen sein muss. Freilich hat man sich noch das reiche Gepränge des babylonischen Kultus hinzuzudenken, um die nachhaltige Wirkung zu begreifen.

Vergil hat im Schwur des Latinus (XII 206 ff.) den Homer nachgeahmt. Bei Vergil könnte man einen Beleg für die oben beschriebene Entwickelung erkennen, denn seine Formulierung des Schwurs ist der babylonischen Beschwörung weit ähnlicher, als die homerische, es heisst nämlich bei ihm: Wie dieses Scepter nie wieder Laub tragen und Schatten spenden wird, nachdem es einmal etc. Daran schlossen sich dann Statius (Theb. VII 552) und Valerius Flaccus an (III 707). Vergleichen liessen sich vielleicht auch die Stellen Ev. Marc. 11, 13 u. 13, 28, wo Jesus den unfruchtbaren Feigenbaum verdorren lässt. Dass Bäume, die Unheil angerichtet haben, verwünscht werden, findet sich im Indischen. ${ }^{1}$ ) Auch Horaz erleidet ja Übles durch einen Baum und verwünscht ihn deshalb (c. II 13).

Auffallend umständlich ist Homer bei dem so oft sich wiederholenden Fall der Einführung eines Redenden: Er sprach- und rief die geflügelten Worte, er sagte das Wort und er sprach etc. Ebenso im babylonischen Epos, wo die Reden meistens mit einem: „er that seinen Mund auf und sagte" eingeleitet worden." $)$ Bei Homer sprachen die Helden

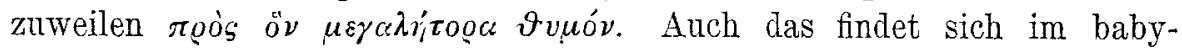
Ionischen Epos, auch da spricht wohl die Göttin "zu ihrem Herzen“ (JENSex, Mythen u. Epen 211, 11 f.; 223, 13 f.). Formelhaft erstarrt sind bei Homer anch die ständigen Beschreibungen, wie jemand sich durch Wassergüsse und Waschung zur Mahlzeit rüstet. Da heisst es dann immer :

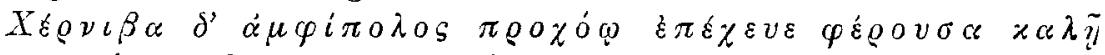

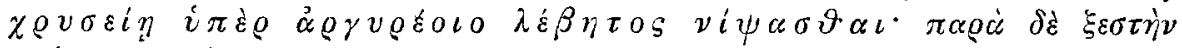

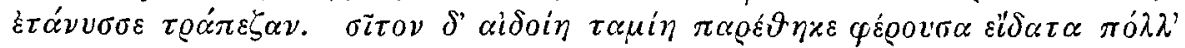

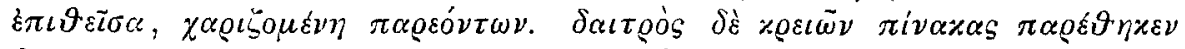

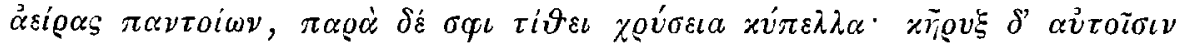

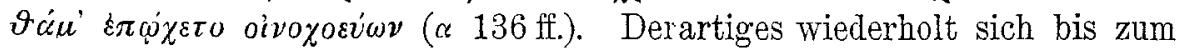

1) Oldenberg, Relig. d. Rigv. 518.

2) S. P. Janswa, Assyrisch-babylonische Mythen und Epen. Keitinschriftl. Bibliothel VI, S. 107,$38 ; 109,8,18 ; 111,9 ; 139,27$ u. ̈̈. 
Überdruss bei Homer, ebenso wie das Niedersetzen auf den Thron, das Unterschieben des Fussschemels u. a. Nun heisst es in einem Symposion, der Schilderung eines Königsmahls auf einer assyrischen Inschrift:')

Der erste Zungenmeister

steht gegenüber zur Aufwartung der Tafeltücher,

Die schmutzig sind, empfängt er, giebt reine,

Die schmutzigen Servietten empfängt er, giebt reine

Der erste ( - - ) vor dem Gefäss (?) mit dem Wasser der Hände steht - - hebt hoch das Wasser, giesst aus das Wasser, schüttet es a uf die Hand.

Man sieht, wie jene homerischen Formeln mit uralten Vorbildern übereinstimmen. Dass die alten Babylonier einen guten Trunk wohl zu schätzen wussten, ersieht man ja auch noch aus bildlichen Darstellungen, ebenso wie die Ägypter derartige Scenen, oft mit grossem Realismus, darstellten.

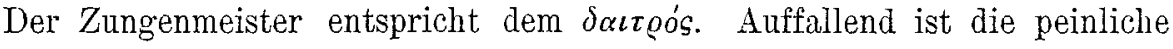
Sauberkeit, die"sich in dem schnellen Wechsel der Servietten kundgiebt, das geht über Homer hinaus, bei dem nichts hiervon verlautet. In den verlorenen 15 Zeilen der Inschrift mag noch manches gestanden haben, was sich auch bei Homer findet. Die Art, wie der König hier beim Mahl von allen Seiten bedient wird, erinnert fast an die Hofümter des Mittelalters, Mundschenk, Truchsess u. s. w.

Wenn es dann weiter heisst (Rev. 18):

"Der Hausmeister steht auf, rezitiert das Werk des Sängers", so entspricht das auch homerischer Sitte, wo kein Nahl ohne das Lied des Sängers verlaufen darf. Abweichend ist hier nur, dass der Hausmeister für den Sänger, nicht dieser selbst auftritt, wie Phemios oder Demodokos. Zu den Obliegenheiten des Hausmeisters also gehörte auch die Rhapsodenkunst, eine für die Geschichte des Sängertums interessante Notiz. Die Herrlichkeit war aber nicht von langer Dauer.

Rev. $22 \mathrm{ff}$. Die Grossen gruppieren sich paarweis - - stehen da der zweite besorgt die Öfen.

Also strenges Hofceremoniell; die Heizung der Öfen erinnert übrigens an Alkaios:

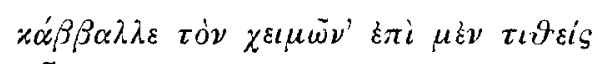

oder Horaz' Nachahmung (c. I 9, 5):

Dissolve frigus, ligna super foco

large reponens.

Wie manches in der äolischen Lyrik mag so auf orientalischem Einfluss beruhen. Alkaios erwähnt ja selbst Familienbeziehungen zu Babylon.

1) Nach F. E. Perser, Studien zur orientalischen Altertumskunde, Mitteilungen der Vorderasiat. Ges. 1898 S. 25.3 Z. 16 ff. 
Gerade solche volksliedmässigen Motive erhalten und vererben sich erstaunlich lang, und man kann Gedanken, die noch jetzt im Volksmund leben und ganz modern anmuten, bis in graues Altertum hinauf verfolgen, wie z. B. Goethes "Liebhaber in allen Gestalten" inhaltlich bis nach Ägypten hinaufreicht. ${ }^{\text {) }}$

Die stärksten Helden werden indirekt dadurch gerühmt, dass andere Helden ihnen auszuweichen suchen und ihnen nicht zu begegnen wagen. Hektor trotzt allen Achaiern, nur dem Peliden schent er sich zu begegnen (cf. auch $H$ 113, $A 542, N 356$ ). Im babylonischen Schöpfungsepos heisst es Z. 36 (J J zu begegnen, insgesamt elf machte sie jene Brut, wobei "denen nicht zu begegnen" als ein Epitheton zu dem Objekt aufzufassen ist, also = unnahbar. Z. 53: "Ich entsandte Anu; der vermag nicht, ihr zu begegnen, Nugimmud fürchtete sich und kehrte zurïck", ebenso Z. 111.

Bei Homer und anderen Dichtern gleich beliebt ist die Parech ese. Es ist unnötig, Beispiele anzuführen, sprichwörtliche Geltung haben einige,

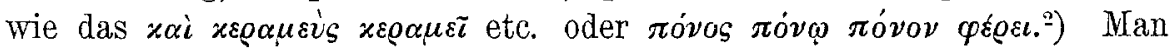
findet die Parechese in der Bibel sowohl wie im Rigveda und auch sonst öfters. In besonders hervorstechender Weise erscheint sie im Babylonischen, wo sie mit Antithesen und Responsionen verschiedener Art verbunden ist, 7. B. in den zitierten Tafeln (S. 3, 20 ff. Z Z

"Hat er Vater und Sohn entzweit, Sohn und Vater entzweit, Mutter und Tochter entzweit, Tochter und Mutter entzweit, Schwieger und Schnur entzweit, Schnur und Schwieger entzweit, Bruder und Bruder entzweit, Freund und Freund entzweit, Genossen und Genossen entzweit?

oder (JENSEN l. c. S. 67):
Meerland soll Meerland,
Mesopotamien Mesopotamien, Assyrien Assyrien, Den Elamiten der Elamit, Den Kassiten der Kassit, Den Beduinen der Beduine, Den Nordländer der Nordländer, Den Lullubäer der Lullubäer,

1) S. m. Ausf. in der Sonntagsbeilage der ${ }_{n}$ Kölnischen Zeitung “ ${ }^{\star}$ v. 28. Dezember 1902. 2) Vgl. $A 255, B 363, A 351, N$ 130, $\Xi 130, \Pi 111,215, \Phi 286$, Tyrtaeus II $31 \mathrm{ff}$. Demokrit fr. 142 Diels u. a. m. Bekker, Homer. Blätter I 185 ff. Ameis-Hentze zu a313. Vоцскимам, Griech. Rhet. 515.

Beitrïge z. alten Gesehichte III 3. 
Land Land, Haus Haus, Menschen Mensch,

Bruder Bruder nicht verschonen. ${ }^{1}$ )

Ganz ähnlich Hessod, wo er das 5. Zeitalter schildert $\varepsilon \times i_{\eta}, 182 \mathrm{ff}$.

Die Anklänge sind fast wörtlich! Vgl. anch Ev. Natth. 10, 21. Auffallend ist die Vorliebe für die Antithese, z. B. (Zimmers 5):

(31) Hat er einen Gott gekränkt, eine Göttin verachtet?

(37) Im Kleinen gegeben, im Grossen verweigert, Zu Nein Ja, zu Ja Nein gesagt

(55) War er mit dem Nunde aufrichtig, im Herzen falsch, Mit dem Munde voller Ja, im Herzen voller Nein,

$(9,122)$ Bei den Göttern des Himmels, den Heiligtümern der Erde forscht er,

(124) Beim Ausgang aus der Stadt und beim Eingang in die Stadt forscht er,

und so liessen sich zahllose Beispiele für diese durch Parallelismus nicht genügend erklärte Symmetrie der Antithesen anführen. NoRden in seiner Antiken Kunstprosa geht an diesen, für die Stilgeschichte aller Völker wichtigen Gebiet aclitlos vorüber. Es ist aber nicht zu bezweifeln, dass der geschmückte Rednerstil weit älter ist als Korax und Tisias, als Heraklit und die Griechen ïberhaupt! Doch davon an anderer Stelle mehr.

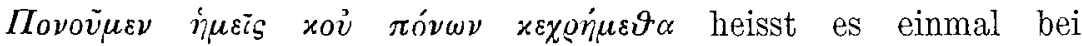
Euripides. Die Behauptung wird verstärkt durch eine gleich danebengestellte Litotes. Das findet sich öfters bei den Griechen, auch bei den Orientalen. ${ }^{2}$ ) Für das Babylonische möchte ich Folgendes anführen (Zimuern 1. c. $5,43 \mathrm{ff}$.) :

(Hat er) falsches Geld genommèn, rechtes Geld nicht genommen, (einen rechtmässigen Sohn enterbt, einen unrechtmässigen Sohn eingesetzt), falsche Grenze gezogen, rechte Grenze nicht ziehen lassen?

Ferner: Welches trübes Wasser trinkt, reines Wasser nicht trinkt."3)

Für die hebräische Poesie lat E. KonxG ${ }^{4}$ ) manche Analogien beigebracht und es zeigt sich deutlich, dass anch auf diesem Gebiet viele Ähnlichkeiten zu finden sind. Vgl. aus der buddbistischen Litteratur „Begabt ist der Asket Gotamo mit den 32 Merkmalen eines grossen Mannes, vollständig, nicht unvollständig " Neumans, Reden Buddhos II 539. (Vgl. auch das. I 148, II 586 ff., $630 \mathrm{ff}$. u. a.)

Als man am Ende des 18. Jahrhunderts das Stilideal der antiken

1) Vgl. Jensen, I. c. S. 67 a. 237,112 u. a. Beispiele aus der Bibel und dem A rabischen bei Kókic, Stilistit etc. S. 285. S. u. S. 25 Anm. 4.

2) S. Wexman, Fleckeis. Jbb. Supplbd. 1886 S. 478. Benker, Homer. Bl. II 222.

3) König Kutha bei Jexsen, Mythen und Epen 291, XI 3 b. Ein ägyptisches Beispiel bei Erman, $\ddot{A g}$. S. 371

4) Stilistik S. 45 ff. 
Kunst entdeckte, ergab sich als ein Hanptmerkmal der Denk- und Ansdrucksweise des Altertums im Gegensatz zur unsrigen das Plastische und Architektonische, eine Vorliebe für das Symmetrische, Cyklische. Der orientalisch beeinflusste Hell en is m u s pllegt das Cyklische in der bildenden und redenden Kunst, offenbar unter östlichem Einfuss. ${ }^{1}$ ) Auch bei Hestod in den Eöen u. a. tritt es hervor und wirkt auch da wie etwas Angenommenes. Die Alexandriner haben das wohl nicht nur von Hesion und seinem Kreis übernommen. Das Babylonische ist nun von alledem voll.

Erinnern die Thontafeln doch zuweilen schon äusserlich an mathematische Berechnungen, wenn Wort unter Wort eingegraben dasteht. Man möchte fast von einem geometrischen Stil der Schrift reden, die ja ursprünglich auch selbst bildende Kunst war. Der Schreiber war der gelehrte Mann. Mit Stolz rühmt Asurbanipal „die edle Tafelschreibekunst, wie unter meinen königlichen Vorfahren keil einziger solche Kunst erlernt hatte" (Zimmers S. 13, 199), vermöge derer die königliche Bibliothek seiner Hauptstadt entstanden war. Man weiss, wie hoch auch in Ägypten die Schreiber geachtet wurden. Thr Streben nach symmetrischem, elegantem Aussehen der schwierigen, umständlichen Schrift hat ganz offenbar auch ihren S.til beeinflusst. Das ging dann vielleicht auf die griechischen Steinmetzen über und macht sich wohl in der sauberen Stichometrie der Schreiber bemerkbar. Der Stil aber, soweit er sich als ,antiker" Stil vom modernen unterscheidet und uns seltsam architekturhaft anmutet, beruht vielleicht in allerletzter Linie auch auf der edlen Tafelschreibekunst mit ihrer monumentalen Symmetrie und Schönheit, vielleicht auch auf der Kunstfertigkeit, die man bei der Überwindung des schwierigen Schreibmaterials anzuwenden hatte. Da wurden parallele und senkrechte Linien gezogen und da stand oft Wort unter Wort. Tabellen waren in ihrer Gleichmässigkeit am meisten geeignet, ein schönes Schreibprodukt darzustellen, waren auch am bequemsten, sie boten den gefälligsten Anblick. Antithesen, Parallelismen ergaben gefällige Gruppen auf der Tafel und wurden daher bevorzugt. Inschriften auf Statuen etc. dienten bei den alten Völkern nichtnurzur Erläuterung, sondern auch als Arabesken, als Ornament, wie noch jetzt in den Moscheen. ${ }^{2}$ ) Man muss bedenken, dass ein Grossbetrieb, wie später in Rom, wo eine Schar von Sklaven um den Diktierenden herumsass und nachschrieb, nicht vorhanden war, dass nur die Gebildetsten der Kunst mächtig waren. So mag die Vorliebe für manche rhetorische Figur vielleicht hierin ihre letzte Erklärung finden. Natürlich kam dann das Musikalische hinzu und wirkte seinerseits auch auf den Stil ein. Dass aber nicht nur das Ohr, sondern

1) S. Robert, Bild und Lied S. 17 Anm. 12.

2) Vgl. anch Erman S. 383, der für Ägypten dasselbe feststellt. 
in ältester Zeit a uch das Auge zu Rate gezogen wurde, ist recht wahrscheinlich. Vieles Stereotype, Formelhafte und überhaupt das rhetorisch Ornamentale geht möglicherweise darauf zurück. Ein interessantes Beispiel aus späterer Zeit sind die alexandrinischen Figurengedichte! Wie es einst z. B. die Wonne des Schreibers gewesen sein mag, die Worte der Zeile, des Satzes so über den Zeilenraum zu verteilen, dass dieser symmetrisch aussah, dass also, wenn die Zeile eine geringere Zahl von Worten enthielt, diese in weiten Abständen am Anfang, Mitte und Ende der Zeile standen, so dass das Ganze wie mit zierlichen Arabesken bedeckt aussah (nie wieder hat die Ästhetik der Schrift solche Bedentung erlangt), wie es ihn frente, immer wieder, 20 oder 30 mal dasselbe Zeichen an das Zeilenende zu setzen, so erlabte sich der Alexandriner an jenen carmina figurata. Vergleichbar wären etwa die oft dreieckig oder keilförmig endenden Handschriften der Mrönche, oder anch ältere Drucke. (Vgl. „Nein Herz dichtet ein feines Lied. - Meine Zunge ist ein Griffel eines guten Schreibers" Psalm 45, 2.) Das zieht sich, mehr und mehr erblassend, doch durch das ganze Altertum hin und erhält sich am längsten im Stil der romanischen Völker. "Ich kam, sah; siegte" klingt unbequem, man hört keinen Abschluss, daher sagen wir: "Ich kam, sah und siegte", das "und" vor dem letzten Glied hat seinen guten Grund, es beruhigt das $\mathrm{Ohr}$, es sagt voraus: jetzt kommt der Schluss! Veni vidi vici klingt zwar nicht minder unbequem, aber der Römer hörte das nicht, er sah es zunächst gleichsam in Stein gegraben, und dann wird es klar, warum er nicht sagte: „et vici! Das hätte die Symmetrie gestört, oder er musste überall et setzen, dann war das Gleichmass hergestellt. Ebenso im Griechischen, entweder immer xai oder nie! So lassen sich vielleicht noch manche stilistischen Eigentümlichkeiten des Altertums erklären.

Das Tabellarische zeigt sich im babylonischen Epos, wenn z. B. Ištar durch die 7 Thore der Unterwelt geht und jedesmal einen Teil ihres Schmuckes verliert und nachher bei der Rückkehr an jedem Thor das ihr Genommene zurückerhält (ähnlich im ägyptischen Totenbuch), oder wenn bei dem Adlerflug des Itana und seinem nachherigen Absturz jedesmal die Stationen des Weges angegeben werden, oder bei Gilgamesch' Hadesfahrt. Periodisches auch bei Barbarossa und Cidher, die mit arabischen und babylonischen Mythen zusammenhängen. ${ }^{1}$ ) Das ist so monoton wie bei Äschylus die Beschreibung der 7 Helden mit ihren heraldischen Abzeichen. Die langen Geschlechtsregister im A. T. und in Hesiods Theogonie gehören in dieselbe Kategorie. Geographie, Reisetagebücher, Statistiken gaben Anlass zu langen Registern. Das ist erkennbar in dem biblischen Bericht über die „Reilien und Lagerstätten des

1) S. Merssner, Archiv für Rehrgionsgeschichte 1902, $228 \mathrm{f}$. 
Volkes Israel" (Mos. 4, 33), in Äschyuus' Wegbeschreibungen (Agamemnon, Prometheus u. a.) und vielleicht schliesslich selbst in $\mathrm{X}_{\text {ENOpHONS }}$ Anabasis, dessen eintönige Aufzählungen der unaufhörlichen Tagemärsche und Parasangen ebenfalls hier zu erwähnen sind. Homers Schiffskatalog, die Monotonie mancher Kampfbeschreibungen, der Schild des Achilleus, manches

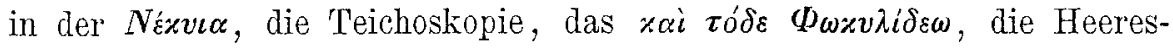
kataloge bei Choirilos und Herodot, der Frautenspiegel des Semonides u. a. gehören schliesslich mellr oder weniger anch hierher.

Im Gilgameschepos wirbt Istar um die Liebe des Helden. Dieser erwidert ilhr mit einer Aufzählung all der Sterblichen, denen Istars Liebe zum Verderben gereicht habe. In der Odyssee führt Kalypso, als sie Odysseus frei lassen soll, einige Fälle auf, in denen die Liebe sterblicher Männer zu Göttinnen durch den Neid der Götter gestört wurde ( $\varepsilon 118$ ff.). Dione tröstet ihre verwundete Tochter durch Heranziehung einer Reihe von ähnlichen Ereignissen, von Fällen, in denen Götter im Kampf mit Sterblichen Wunden davontrugen ( $E$ 381). So geht die Vorliebe für cyklische Erzählungen bis ins Einzelne. Auch der epische Kyklos zeigt Spuren solcher Neigungen. Die vó Faden eine Schnur von Einzelgeschichten aufzureihen. Für das Ägyptische ist der Märchencyklus des Papyrus Westcar (a. 17. Jahrh. v. Chr.) hier anzufülhren, in dem König Cheops dieselbe Rolle spielt wie Harun al Raschid im arabischen Cyklus. Noch ähnlicher ist die Anlage in den "Sieben weisen Meistern", die schwerlich, wie $\left.W_{\text {ILAmowitz }}{ }^{1}\right)$ meint, von den sieben Weisen Griechenlands abhängen, sondern offenbar altorientalisches Erbstïck sind.

Die Anaphora blüht bei den Babyloniern ursprünglich wohl nicht als ein Mittel der pathetischen Rede, sondern war wegen der Uniformität,

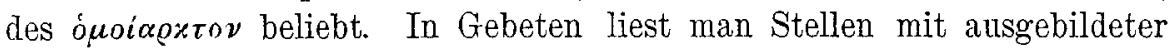
Anapher: "Lass ausser Acht, dass ..., lass ausser Acht, dass ... etc." ") In diesen Gebeten findet sich übrigens auch eine ganz eigentümliche Erscheinung, die auffallend an altgriechische, strophische Chorlyrik erinnert. Deutliche Responsionen treten auf. Ein solcher Gesang ist in fünf Teile gegliedert: erst ein Gebet an den Gott, dann Begründung des Bittgesuchs, darauf eine Abwendung böser Vorbedeutungen in anaphorischer Aufreihung, 4) Wiederholung des 2. Teils in fragender Form, möglichst wortgetreu sich anschliessend, endlich ein Schlussgebet. ${ }^{3}$ ) Strophische Einteilung ist ja im Indischen und Iranischen ganz geläufig, vielleicht nach babylonischem Muster. A. JeREMIAs erzählt von einem unveröffentlichten Fragment aus der Bibliothek Asurbanipals, auf dessen Rückseite es heisst:

1) Hermes 25, 198.

2) S. Kniptzon, Assyr. Gebete an den Sonnengott. Leipzig $1893 \mathrm{~S} .78 \mathrm{ff}$.

3) S. Knudtzon 1. c. Havit, Verhandl. d. V. Orientalistenkongr. II. Sekt. 269. 
"Es wehklagten die Gattinnen, es antworteten die Freunde." Ahnliche abwechselnde Trauergesänge finden sich ja in Aischylos' Persern und anch sonst. $\left.{ }^{1}\right)$ - An einer stilistischen Eigentümlichkeit lässt sich unzweifelhaft nachweisen, dass sie von den Schreibern selbst herrührt, an der Akrostichis, die ans Babel stammt.") Ja, es kommt hinzu, dass in ältester Zeit die Zeichen ja nicht neben, sondern unter einander gesetzt wurden. Sollte sich etwa ein letztes schwaches Nachgefühl dieses alten Zustandes darin gezeigt haben, dass der alte BabyIonier unwillkürlich seinen Blicken vor der Schrifttafel eine vertikale Richtung gab und so die Anfangszeichen von oben nach unten las? Da ergab denn vielleicht der Zufall einmal ein wirkliches Wort, später half man etwa dem Zufall spielend nach - und erfand die Akrostichis. Daher auch überhaupt das Interesse der Schreiber für das Schriftbild in vertikaler Richtung! Das lat lange fortgewirkt und später, als man vermutet, noch leise, feine Spuren im antiken Stil zurückgelassen.")

Zu üppigster Blüte gedieh der geschmückte Stil im mittleren Reich Ägyptens. Da schwoll die Rede von Chiasmen, Wortspielen und rhetorischen Figuren aller Art, gewiss alles das nicht ohne asiatischen Einfluss. ${ }^{4}$ ) Nach E. Norden beginnt die antike Kunstprosa mit Heraklit und den Eleaten, nach andern schon bei Homer. Sollte sie, wie gesagt, in Wahrheit nicht weit höher hinaufzurücken sein?

Höchst interessant ist übrigens der Hinweis Nordens auf die Thatsache, dass die Alten stets laut lasen. ${ }^{5}$ ) Man sieht, wie die Thätigkeit des Ohrs mit der des Auges verbunden war. Beide ergänzten sich.

Wie stark auf dem Gebiet des Briefstils der Orient gewirkt hat und wie sehr hierin ein bestimmter Schematismus sich ausgebildet hatte und von Volk zu Volk forterbte, lehren die Amarnabriefe.

In das Gebiet der Stileigentümlichkeiten darf man schliesslich anch die Gepflogenheit vieler antiker Dichter rechnen, sich am Schluss des Werkes das Horoskop über den eigenen Nachruhm zu stellen und sich selbst die Unsterblichkeit zu verkünden. Man erklärte das früher durch die grössere Unbefangenheit der alten Völker in diesen Dingen. Indessen sticht ihre Empfindung hierin doch so sehr von der unsrigen $a b$, und andererseits passt der Ausdruck des Selbstgefühls in dieser Stärke so wenig zu der edlen Bescheidenheit und vornehmen Zurückhaltung, die doch sonst immer als ein Bestandteil des antiken Sittenkodex erscheint, dass man gut thut, nach einer historischen Ursache zu fragen. Alkman, Sappho, Mimnermos, ${ }^{6}$ ) Theognis, Pindar, Ennits, Horaz, Properz, Ovid,

1) Vgl. A. Jenemias, Hölle und Paradies bei den Babyloniern. Der alte Orient I 3, 2. Aut. 1903, S. 11. - 2) Nicht aus dem Hebräisehen. S. Philol. 1902 S. 512.

3) Über Akrostichis bei den Ägyptern vgl. BroGscr, Hieroglyph. Grammatite S. 100. - 4) ERman, Ägypten 497. - 5) 1. c. S. 6 f. Augustin conf. VI 3.

6) S. VAHLEN, Ennianae poesis reliquiae p. XC. 
Phädrus u. a. verkünden ihre eigene Unsterblichkeit.1) Bei vielen findet sich die Vorstellung, dass ihr Ruhm von Volk zu Volk wandern, ihr Werk wie Stein und Eisen allen Stürmen der Zeit trotzen werde.

Nun lesen wir die formelhafte Klausel der Beschwörungstafeln, die sich wörtlich am Ende mehrerer Exemplare wiederfindet:"2)

Die Weisheit Nebos .....

schrieb ich auf Tafeln, auf dass ich sie besichtigen und lesen könne, legte ich sie in meinem Palaste nieder, ich, der Herrscher, der da kennt das Licht des Königs der Götter; Asur.

Wer immer sie wegnimmt oder seinen Namen

neben meinen Namen schreibt,

Den mögen Asur und Belit in Zorn und Grimm stürzen, seinen Namen, seinen Samen von der Erde vertilgen.

ebenso S. 41 n. 135.

Ferner Folgendes aus dem Epos::3)

„Und also sprach der gewaltige I(U)ra:

Wer meinen Gesang fürchtet, in seinem Tempel möge Überfluss angehäuft werden,

aber wer ihn fortschafft, soll keinen Weihrauch riechen.

Wer meinen Namen gross macht, soll die Welträume beherrschen,

Wer von der Furchtbarkeit meiner Gewaltigen redet,

Soll keinen haben, der ihm widersteht.

Ein Sänger, der ihn laut singt, soll nicht im Strafgericht sterben,

Und dem Künige und den Grossen soll seine Rede angenehm sein.

Ein Tafelschreiber, der ihn lernt, wird dem Feinde entrinnen, wird in $\langle\longrightarrow$ geehrt sein.

Und im Tempel des Volksheers, wo man beständig meinen Namen nennt, werde ich sein Ohr öffnen;

Im Hause, wo selbige Tafel hingelegt ist, möge I(U)ra ergrimmen und mögen die Sieben niedermetzeln,

Der Degen des Strafgerichts wird ihm nicht nahe kommen, Unversehrtheit ist ihm gemacht,

Jener Gesang mög" immerdar "gemacht werden“, möge bis in (ferne) Zukunft bestehen.

Die Länder, ihre Gesamtheit, mögen ihn hören und meine Gewalt fürchten,

Die Leute aller Wohnplätze mögen ihn lesen und meinen Namen gross machen!"

Der Gott will seinen Worten ewige Dauer verleihen und wendet

1) Vgl. auch Archiv für Papyruskunde II $95 \mathrm{f}$. In der Form des Wunsches dasselbe im Hiob 19. Ähnliches zuweilen im Totenbuch.

2) Zimmeris l. c. S. $13 .-3)$ Janshis 1. e. S. 73. 
sich an die Götter, die Könige, Sänger und Tafelschreiber. Die Priester suchen den Satzungen und Denkmälern ihres Kultus einen unbegrenzten Bestand zu sichern, sie thun es am wirksamsten, indem sie dem Gott selbst ihre Absichten in den Mund legen. Es wird Überfluss im Tempel prophezeit. Den Königen wird erhöhte Wacht verheissen, wenn sie der Hierarchie gefügig bleiben; der Sänger erhält grenzenlosen Ablass und wird sakrosankt, den Mächtigen soll er angenehm sein, ein interessanter Passus, der vortrefflich zu dem passt, was ich an anderer Stelle hierüber ausgeführt habe. $\left.{ }^{1}\right)$ So der schwungvolle Priester. Weit nüchterner, aber auch weit energischer klingt das Edikt des Königs, das auch die anderen Königsinschriften aufweisen. Die Tafeln sollen streng bewacht bleiben, der König behauptet hier, sie geschrieben zu haben, er also tritt an die Stelle des Gottes, der sich als Verfasser des Gesanges bekennt und setzt sich über die Hierarchie hinweg. Niemand soll seinen Namen neben den des Herrschers setzen. Dem Verfasser der epischen Stelle kam es auf möglichst weite Propaganda des Mythos, der Religion an, mit ihr wuchs auch seines Standes Bedeutung, dem König liegt an der Erhaltung der mit seinem Namen signierten Denkmäler seiner Macht. Ursprünglich war es nichts als eine subsçriptio, als ein Insiegel. Allmählich ging es in allgemeinen Gebrauch über, die Nachbarländer übernahmen es, und ihre Poeten verkïndeten ihren Werken ewigen Bestand, nicht um ihre Macht zu dokumentieren, sondern um ihre litterarische Bedeutung in das rechte Licht zu stellen. Horaz und Ovid messen ihres Ruhmes Dauer an derjenigen eherner, unzerstörbarer Denkmäler. Monumentum aere perennius! Pindar vergleicht seine Hymnen gern mit Bildwerken, wie nach seinem Muster unser Platen von einem „erzgetriebenen Bildwerk des Lieds" redet. Bei Sirach heisst es ähnlich (32,7f.): „Wie ein Rubin in feinem Golde leuchtet, also zieret ein Gesang das Mahl. Wie ein Smaragd in schönem Golde stehet, also zieren die Lieder beim guten Wein." Bei Demokrit heisst es (fr. 21 Diels): "Ou

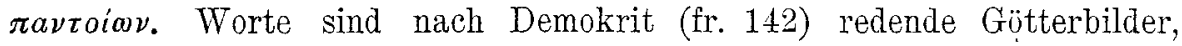
$\alpha \gamma \dot{\alpha} \lambda \mu \alpha \tau \alpha \alpha \omega \nu \eta^{\prime} \varepsilon \nu \tau \alpha$.

Dunkel klang durch alle Völker die Kınde von dem Lande, „aus des Bezirk kein Wand'rer wiederkehrt". Abgesehen von den Neueren findet sich die euphemistische Formel bei Römern und Griechen, bei Catull, Vergil, Properz, Seneca, Apulejus, bei Theokrit, Philitas, Kallimachus, ähnlich auch bei Hesiod, ferner bei den Indern (Rigv. 840,2), Israeliten (Hiob 10,21, 16,22, Sirach 38,22) und Ägyptern. ${ }^{2}$ ) Der Ge-

1) Rhein. Mus. 57, $265 \mathrm{ff}$. Die Lehren, die Telemach $\alpha 345 \mathrm{ff}$. der Mutter giebt, finden sich ähnlich bei Sirach 32, 5 f.: „Irre die Spielleute nicht, und wenn man lieder singet, so wasche nicht darein, und spare deine Weisheit bis zur audern Zeit."

2) "Siehe, nicht giebt es einen, der hingegangen wäre und wiedergekommen", 
danke ist ja recht naheliegend, doch die eigentliche Ursache seiner auffallenden Verbreitung sprang doch erst in die Augen, als man das Lied von Ištars Höllenfahrt ausgrub und da auf der ersten Tafel den imposanten Anfang las:

Auf das Land ohne Ruickkehr, die Erde ...

(setzte) Ištar, die Tochter Sins, ihr Ohr.

Es setzte die Tochter Sins ihr Ohr

Auf das düstere Haus, die Wohnung Irkallas,

Auf das Haus, dessen Betreter nicht wieder hinausgelit,

Auf den Weg, dessen Begehen ohne Rückkehr ist,

Auf das Haus, dessen Betreter des Lichts entbehrt.')

Die finstere Majestät des Ausdrucks rief dies lange Echo bei allen Völkern hervor, am tiefsinnigsten hallte es zurück bei Dante und Shakespeare!

Die gewaltige Schilderung vom Kampfe Marduks mit der Tiâmat ladet zu Vergleichen mit Homer ein. In beiden Fällen geht dem Kampf eine Reihe von mündlichen Herausforderungen und Schmähungen vorans. Der Angreifer stutzt und erschrickt beim Anblick des gewaltigen Gegners. Tiâmat selbst, „die Mutter der Götter," erinnert in ihrem Kampf gegen diese, wenn sie ihre Söhne versammelt, mit furchtbaren Waffen ausstattet und zum Streit gegen jene aufreizt, lebhaft an Gaia, die anch ihre Söhneschar zum Aufruhr gegen die superi zu entflammen weiss. Anšar entbietet Anu und Ea gegen Tiâmat, aber beide sind verzagt. So fürchten sich die Achaier vor dem Zweikanpf mit Hektor und erst Nestors Mahnrede weckt das Ehrgefühl in ihnen durch die Erinnerung an den Kampf zwischen Pyliern und Arkadern; auch da hatte ein Held die Feinde zum Kampf aufgerufen, alle Pylier verzagten vor Ereuthalion, und Nestor, der jüngste, erschlug ihn ( $H$ 132 ff., cf. David). Auch Marduk ist einer der $\mathrm{jüng}$ g sten unter den Göttern (vgl. d. Knaben Isais). Wie dort Aias gegen Hektor, tritt nun Marduk gegen Tiâmat auf. (Schöpfungsepos Tafel III.)

In voller Rüstung, hoch im Streitwagen, in der Hand den Dreizack tritt Marduk der Tiâmat und ihrem Gemall Kingu entgegen. „Wie der ihn erblickte, da ward verwirrt sein Vornehmen, sein Verstand ward benommen, sein Thun verworren." $\left.{ }^{2}\right)$ Auch die andern Götter verzagen. So die Griechen vor Hektor ( $H 92$ ff.), so die Troer am Ende der Mias vor Achillens. Als dieser dem Hektor vor den Thoren Trojas begegnet und ihn zur letzten Abrechnung herausfordern will, da "Extopa $\delta$ ' ẃs

Maneroslied des Londoner Papyrus. „Bis herankommt jener Tag, an dem man landet in Lande, welches das Schweigen liebt. — Nicht ist einer, der [je] wiederkam," dass. nach dem Grab des Neferhotep.

1) JeNSEN S. $81,85 \mathrm{ff}$., 189. - 2) Nach ZmMern, bei Gungec, Schöpfung u. Chatos S. 412 v. $67 \mathrm{f}$. 


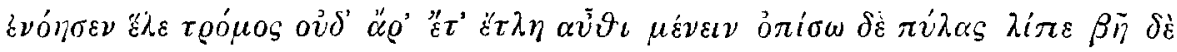

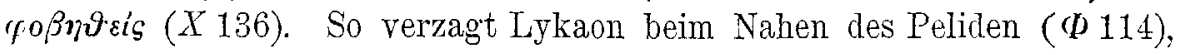
und in den verschiedenen Einzelkämpfen der Ilias findet sich viel Analoges. Diese zahllosen Einzelkämpfe enthalten auch sonst noch viele gemeinsamen Züge. Bei derartigen Schlachtscenen vor Troja mag ein uralter Götterzweikampf vorgeschwebt haben.

Alle verzagen vor Marduk, wie erwähnt, nur Tiâmat bleibt. So hält auch Hektor endlich dem Achill Stand, während die Troer hinter den Manern verharren. Tiùmat redet Marduk znerst an, trotzig fordert sie ihn heraus. So Hektor zuerst den Peliden ( $X$ 250). Aber finster blickend lält Achill dem alten Gegner seine Thaten an den Achaiern vor und weist jede mildere Regung weit von sich ( $X 260$ ff). Auch Marduk ist entschlossen, „der Tiâmat, was sie begangen, hielt er also vor" (76 Znmers). Es folgt eine Rekapitulation der Frevel Tiâmats und eine Schlussdrohung.

Ähnliches findet sich aucle in dem vielleicht durch babylonische Epenmotive beeinflussten Kampf Davids mit Goliath, dem ebenfalls die Drohungen voraufgehen, den Körper des Feindes den Vügeln unter dem Himmel preisgeben zil wollen. Agamemnon warnt den Menelaos ( $\boldsymbol{H} 107 \mathrm{ff.}$.) vor dem Kampf mit dem viel stärkeren Hektor, wie Saul den David (Samuel I, 17, 33).

Ebenso beschwören die greisen Eltern den Hektor, vom Kampf mit Achill abzustehen (X 33-90).

Ehe es zur Entscheidung zwischen Achill und Hektor kommt, wird die Seele des letzteren gewogen. Dasselbe thut Hermes in der Äthiopis vor Memnons Tóde. 0. Gruppe führt das sehr geistreich auf Ägypten zurück (Gr. Mythologie S. 681,6). Im Totenbuch wägt der Gerichtsschreiber Dhuti die Herzen. Auch in Indien war das Motiv bekannt. ${ }^{\text {) }}$ Die Urheimat dürfte wohl in Babylonien, dem Ursprungsort aller Metrologie, zu suchen sein. Hrazei erkennt darin eine Art von Gottesurteil, und dass solche in Babylonien bekannt waren, wissen wir aus dem Gesetzbuch des Hammurabi. $\left.{ }^{2}\right)$

In den Monomachieen tritt gewöhnlich der Held $\mu \alpha \propto \rho \dot{\alpha} \beta \iota \beta \alpha^{\prime} s$ einher ( $\Gamma$ 22, H 213, $N$ 809), man denkt an die Helden ägyptischer Schlachtendarstellungen, wo oft eine Gestalt von überragender Grösse mit einem Schritt die Hälfte des feindlichen Heeres $\mu \alpha \varkappa o \dot{\alpha} \beta t \beta a \dot{~ u ̈ ~ u ̈ b e r s c h r e i t e t . ~ D a s ~}$ ist wohl der ursprüngliche Sinn der Worte, der $\iota 450$ schon verblasst erscheint. Wenn die Helden Homers zuweilen über irdisches Mass erhöht erscheinen und schon durch ihr Äusseres den Feinden Furcht und

1) S. Hinzes, Der Eid 188, 3, der auch noch andere Beispiele anfïhrt.

2) $\S 2$ u. $\S 132$. Vgl. dazu jetzt auch C. F. Lenmans, Babyloniens Kulturmission einst und jetat, S. 45 . 
Entsetzen einflössen ( $\Sigma 221$ u. ö.), so gemahnt das vielleicht ebenfalls an den Orient. „Da er unter das Volk trat, war er eines Haupts länger, als alles Volk" (Samuel 1, 9, 2; 1, 10, 23). Dass hier plastische Kunst vorschwebte, beweist $\Sigma$ 519. Die Götter bildet Hephäst auf dem Schild in goldnen Gewändern, gross und schön, und vom Volk fügt der

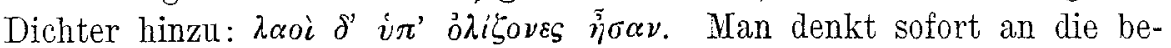
kannten ägyptischen Darstellungen. Andere Beispiele ägyptischen Einflusses auf die Sclild beschreibung hebt A. Mones hervor. ${ }^{1}$ ) Auch an Nehemia 8, 5, wo Esra gleichfalls alles Volk überragt, ist zu erinnern. Auch die Aristieen, besonders die des Odysseus, kann man vergleichen, und zwar mit dem Liede des Pentaur, in dem Ramses allein, von seinem Gefolge verlassen, die Feinde ringsum niederschlägt. Vgl. $A 402 \mathrm{ff}$. Er ruft die Gottheit an und erinnert sie, genau wie die Helden der Ilias, an alles Gute, das er ihnen erwiesen. So ragt er auf Bildern hoch über allen Feinden empor, vom hohen Streitwagen die Pfeile gegen ihr Heer schleudernd, und sichtbar steht die Gottheit ihm bei und verhilft ihm zum Siege. Das Lied des Pentaur ist übrigens schon früher mit der Ilias verglichen worden. Anch in der Sage vom Freiermord besiegt ein Held durch göttlichen Beistand einen ganzen Schwarm von Feinden.

Auf einem Tempelrelief erscheint Ramses III. dem Heere gegenüber in mächtiger Stellung, ihm zu Häupten schwebt die Göttin des Nordens, und zwar in Gestalt eines Geiers (Ermax l. c. 712), eine suidsemitische, bei den Arabern besonders vertretene Anschauung. ${ }^{2}$ ) Vergleicht man den Zweikampf des Hektor und Ajas, so heisst es $(\boldsymbol{H}$ 58), nachdem Hektor die Griechen angerufen und alle sich gelagert haben:

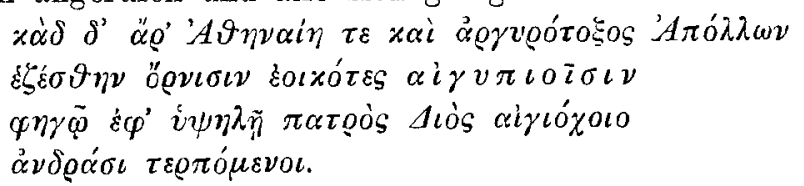

Gehört hierher vielleicht auch die ägyptische Geierhaube? (Erman 314).

Weniger Gewicht ist auf Folgendes zu legen, da die Vorstellung: ziemlich naheliegend und die Annahme gegenseitiger Abhängigkeit also nicht notwendig ist. Wenn nämlich Diomedes mit einem Löwen verglichen wird, der, durch den Hirten leicht verwundet, nur um so wütender in die Herde fällt ( $E 136 \mathrm{ff}$.), so stimmt das genau mit der Bibel überein, wo der Prophet sagt (Jes. 31,4): „Gleich wie ein Löwe und ein junger Löwe brüllet über seinem Raub, wenn der Hirten Menge ihn anschreiet; so erschrickt er vor ihrem Geschrei nicht und ist ihm allch nicht leid vor ihrer Menge," so werde der Herr die Feinde schlagen.")

1) Revue archéol. 1901 S. $198 \mathrm{ff}$ - 2) S. Smrre, Rel. d. Semiten S. 171.

3) Beiläufig sei bemerkt, dass die Vergleichung des Aias mit einem Kunstreiter und Tänzer sehon ähnlich in einem ved. Hymnus an Indra vorkommt (Rigv. 476). Vgl. auch Il. 18, 604. Auf einem Wandgemälde in Knossos findet sich ein galoppierender 
Der babylonische Etanamythos erzählt, wie die Schlange, um sich am Adler zu rächen, in einer Stierhaut verborgen, auf den Adler wartete. Dieser fliegt trotz vorheriger Warnung heran, die Schlange erfasst ihn und zerschmettert stürzt er hin.1) Wie eine Reminiscenz an das babylonische Epos klingt folgender Homerische Vergleich (M 200 ff.):

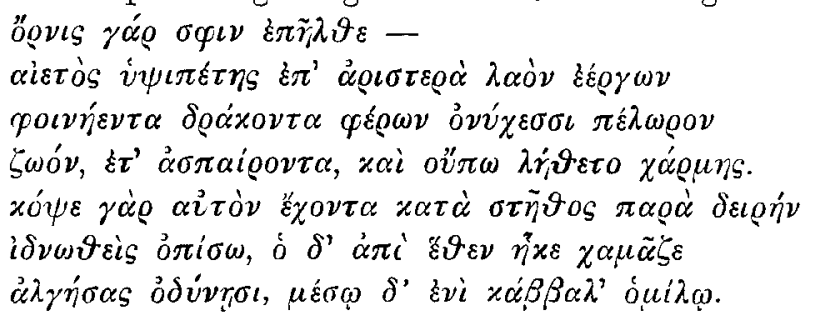

Der Ausgang ist freilich anders, aber auch hier ist von den Jungen des Adlers die Rede, die im Etanamythos eine so wichtige Rolle spielen.

Das Motiv der Teichoskopie hat immer lebhaften Beifall gefunden, das beweist die Fülle der Nachahmungen in der Weltlitteratur: die Sage vom Eisernen Karl im Langobardenreich, Goethes Gütz, Schillers Jungfrau, Kleists Prinz v. Homburg, Uhlands Ludwig d. Baier III, 3 u. a. m. Eine Teichoskopie findet sich übrigens auch in der Edda (Sn. Edda 19, 24). Auch Homer hat das nicht erfunden, das kann man noch aus älteren ähnlichen Episoden der orientalischen Litteratur schliessen. Wenn Samuel sich die Söhne des Isai einzeln beim Opfer vorführen lässt und über jeden urteilt, $o b$ er der Erwählte des Herrn sei (Sam. 1, 16), oder wenn der Knabe auf der Warte die Kinder des Königs herankommen sieht (Sam. 2, 13, 34), oder wenn David zwischen zwei Thoren sitzt und der Wächter auf der Mauer nun in lebhaftem Dialog mit dem König meldet, was er sieht, wie die beiden Boten kommen und von der Schlacht und dem Ende des Absalom berichten (ib. 2, 18, 24ff.), so sind das deutliche Ansätze zu Teichoskopien. Hinter Wall und Mauern spielte sich damals alles Leben ab, die Worte des Wächters bedenteten in jenem Zeitalter oft ein Schicksal für Tausende. Die Himmelsleiter Jakobs and ähnliches bei Ägyptern und Persern führt Gunker (Genesis S. 289) auf die babylonischen Thürme mit ihren Stockwerken zurïck. Auf diesen beruhte m. E. offenbar auch der Aufflug des Etana, bei dem in bestimmten Abständen geschildert wird, wie die Erde sich jedesmal dem Emporschwebenden darstellt, auch das eine Art von Teichoskopie. Wenn bei Naturvölkern öfters von einer Pfeilleiter die Rede ist, auf der man zum Himmel aufsteigen kann (FrobenIUs, Weltanschauung der Naturvölker S. 30), so ist der Zusammenhang mit dem vorher Erwähnten unverkennbar.

Stier, auf dessen Rücken ein Kunstreiter steht, und zwar auf den Händen, eine Frau bat sich an die Hörner des Stiers gehängt, eive andere holt hinter ihm zum Sprunge aus. 1) C. F. Lehmann, Zeitschr. f. Assyriol. IX (1894) S. 314/6. Jensen 1. c. $103 \mathrm{ff}$. 
An die Episode von Glankos und Diomedes und den Waffentausch erinnert folgende Bibelstelle: „Und Jonathan und David machten einen Bund mit einander; denn er hatte ihn lieb wie sein eigen Herz. Und Jonathan zog aus seinen Rock, den er anhatte, und gab ihn David, dazu seinen Mantel, sein Schwert, seinen Bogen und seinen Gürtel" (Sam. 1, 18, 3 ff., vgl. Patroklos in Achills Rüstung $\Xi 10$ ff.). Es findet zwar kein eigentlicher Tausch statt, aber in beiden Fällen wird der Ärmere durch des Reichen Edelmut wohlbedacht und die Freundschaft sofort durch die That besiegelt. Ein Niederschlag hiervon findet sich vielleicht, wenn auch recht spät, in der Sage vom Rübezahl und dem schwedischen Rittmeister, in der auch beide die Kleidung tanschen und der Rittmeister sich dann zunächst enttäuscht, zuletzt aber reich beschenkt findet. ${ }^{1}$ )

Wenn Odysseus bei Eumaios weilt und Athene hinzutritt und nur von Odysseus und den $\mathrm{Hunden}$ erkannt wird, nicht von Telemach ( $\pi$ 162), oder wenn Argos allein seinen Herrn wiedererkennt, so hat das anch ein biblisches Gegenstück, und zwar in Bileams Eselin, die allein den Engel sieht und trotz aller Schläge ihm ausweicht. Auch sie gewinnt Sprache, wie Achills Rosse, und beklagt sich bei ihrem Herrn, wie jene steht sie der Gottheit näher, als ihr Herr. Rèdende Rosse finden sich auch im Avesta, dort beklagen sie sich bei ihrem Herrn über die schlechte Behandlung, die ihnen zuteil wird, ebenso wie Bileams Eselin (s. Geiger, Ostiran. Kultur S. 352). Wie diese, weigern sich auch die göttlichen Rosse des Achill ( $P 430$ ff.) trotz aller Geisselhiebe vom Platz zu weichen und ihren Herrn zu verlassen. Wen der Hund nicht kennt, gegen den springt er an und umbellt ihn ( $v$ 15), vor Athene aber fliehen die Hunde ohne Gebell in den Winkel, wie die Eselin dem Engel scheu ausweicht und, in die Enge getrieben, vor ihm in die Kniee fällt, das Sinnbild der reinen Seele, die sich „des rechten Weges wohl bewusst" bleibt.") Vielleicht darf in diesem Zusammenhang an die Stelle im Gilgameschepos erinnert werden, wo gesagt wird: nachdem Eabani die Überkraft verloren hatte, erkannte ihn sein Vieh nicht und floh vor ihm. In nordischer, deutscher u. a. Sage finden sich ähnliche Züge vom Hund, der mit Geistern im Bunde steht (Mephistopheles). Der trene Argos findet sich übrigens schon in Ägypten, wo in einem Märchen der 20. Dynastie von einem Prinzen die Rede ist, der eher sterben, als sich von seinem oft bewährten braven Hunde trennen wollte (Ermas 334). Im 17. Buch des Mahâbhârata soll Yudhischthira mit Indra in dessen

1) Von einem Fall des Kleidertausches als Zeichen der Erkenntlichkeit wusste mir C. F. Lenmann aus eigner Erfahrung unter persischen Kurden zu berichten. Andere Beispiele aus dem Altertum s. bei Sмiтн, Rel. d. Sem. S. 116.

2) Vielleicht ein Rest alten Eselskults? Vgl. Midas u. a. Äbnlich furchtet sich der Elefant vor Buddha (S. Oldenberg, Buddha S. 182). 
Wagen zum Himmel fahren, weigert sich aber, es zu thun, wenn ihm nicht gestattet wird, den Hund mit auf den Wagen zu nehmen. Ähnliches auch sonst. Nach einer Version des Märchens von Sneewittchen ist ein Hund der einzige und letzte Vertrante der Königin; ihn fragt sie, wer die Schönste im ganzen Land sei, und sie muss sich auch von ihm die bittere Wahrheit sagen lassen (Grimm, Kinder- u. Hausm., Bd. III zu 53: Sneewittchen). ${ }^{1}$ ) Wie Eabani von seinem Vieh, so wird Aktäon von seinen Hunden nicht mehr erkannt. Trostlos jagen sie nach seinem Tode umher und lassen sich nicht beruhigen, bis Cheiron ein Bild des Aktäon anfertigt und es ihnen zeigt (Apollod. III, 4, 4).

Aktäon lässt sich übrigens auch sonst mit einer Stelle des Gilgameschepos vergleichen. Er wird von der zürnenden Artemis oder (nach Akusilaos) von Semele, die er liebte, in einen Hirsch verwandelt und von seinen eignen Hunden zerrissen (Apollod. 1. c. Ov. met. III, 173 ff.). Im babylonischen Epos (tab. VI, 58 ff.) heisst es (nach $J_{\text {FiNSEN }}$ ):

Als den Hirten der Herde du (Ištar) liebtest,

Der dir beständig Salz hinschüttete,

Dir täglich Zicklein schlachtete,

Schlugst du ihn und verwandeltest ihn in einen wilden Hund.

Es verjagen ihn seine eignen Hirtenknaben

Und seine Hunde reissen sein Fell.")

Diese Worte spricht Gilgamesch zu der ihm ihre Liebe antragenden Ištar und fügt noch viele bittere Worte über ihre Unbeständigkeit und Willkür gegen die Sterblichen hinzu. Ištar flieht zum Himmel, klagt ihrem Vater Anu ihr Leid und bittet um Bestrafung des Helden. So flieht Aphrodite zum Zeus, als Diomedes sie verwundet und illr ver-

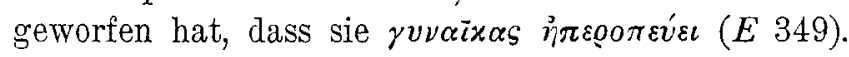

Auf die Gleichungen Gilgamesch-Eabani = Achill-Patroklos = DavicJonathan u. a. hat man schon hingewiesen. Das geht oft bis ins Einzelne. Nach Patroklos' Fall ist auch Achill welmmütig und gedenkt wiederholt des Todes. So übermannt das Todesgefühl den vereinsamten Gilgamesch, der nun auch sein Ende voraussieht. ${ }^{3}$ ) Nachdem Abner, Davids Waffen-

1) Vgl. auch das von Brückner (Jahrb. d. archaol. Inst. 1902 S. 39 ff.) beschriebene Neapeler Grab mit dem Bildnis des zu dem Manne aufblickenden Hundes, und Dümmler, Philol. 1897, 12 Anm. 14 über Kriegshunde. Über die Heiligkeit des Hundes bei den Persern s. Joex, Sokrates, II S. $950 \mathrm{f}$. In einem aramäischen Märchen wird ubrigens auch ein Esel redend und hellsehend eingeführt, aber es handelt sich da nur um eine Fiktion, um so durch List einen $Z$ weck zu erreichen, also ein rationalistischer Abklatsch alter Mythologie. (S. M. Lidzbarskr, Geschichten und Lieder aus den neuaramaischen Handschriften d. Kgl. Bibl. zu Berlin 1896 S. 208 f.)

2) Vgl. auch Wochenschr. f. llass. Philol. 1903 Sp. 284, wo ich das eingehender behandelt habe.

3) JENSEN 1. c. 201. cf. Psalm 55, 5. Mein Herz ängstet sich in meinem Leibe und des Todes Furcht ist auf mich gefallen, cf. 18, 5: Es umfingen mich des Todes Baude und die Bäche Belials erschreckten mich. 
gefälnte, getötet ist, rüstet das Volk ein Yahl, David aber schwört, nichts zu sich zu nehmen, ehe die Sonne untergeht. ${ }^{1}$ ) Nach einem Kampf gegen die Philister ruft Saul aus: "Verfucht sei jedermann, wer etwas isset bis zum Abend, dass ich mich an meinen Feinden räche." Da ass das ganze Volk nichts.") Vgl. T205ff., wo Achill sich ganz ähnlich äussert.

Mit dem Gilgameschepos berührt sich Homer in der ganzen Technik; wie dort die Geschichte der grossen Flut, werden in der Odyssee die Fahrten des Helden eingeschoben und beide in der ersten Person erzählt. Entsprechendes liest man in ägyptischen Märchen, ${ }^{\prime)}$ ) auf deren sonstige Übereinstimmungen mit dem Epos man schon hingewiesen hat. $\left.{ }^{4}\right)$ Man dachte eben an den Erzähler auf dem Markt, den Rhapsoden, dem die Form der Ich-Erzählung zum Hebel der Phantasie wird, der alles, indem er es scheinbar von sich selbst erzählt, lebendiger vor sich sieht und so wie Odysseus oder Äneas bei Dido oder noch heut der sibirische Rhapsode ${ }^{5}$ ) sein Gespinnst abrollt, bis die ambrosische Nacht vergeht und am Himmel die Sterne erbleichen (cf. $\lambda$ 330, $\iota 5$ ff.).

Vergebens wird der Bogen des Odysseus im Freiersaal anfgestellt, niemand vermag ihn zu spannen, als der Bettler. Die Äthiopen schicken dem Kambyses einen Bogen und lassen ihm sagen, wenn er ihn spannen könne, werde er die Äthiopen besiegen. ${ }^{6}$ ) Von Amenophis II. heisst es in einer Inschrift ${ }^{7}$ ): „Er ist ein König mit wuchtigem Arm, und es giebt keinen, der seinen Bogen spannen kann unter seinen Soldaten, noch den Fürsten der Fremdländer und den Grossen von Rtnw, weil seine Kraft grösser ist, als die jedes anderen Königs," und in dem Märchen von Sinuhe findet sich folgende Stelle (62): "Er tötet, und niemand entgeht seiner Waffe. Es giebt keinen, der seinen Bogen spannen kann". Erman bringt das mit Herodot zusammen. ${ }^{9}$ ) David sagt in seinem Lobgesang für die Errettung von seinen Feinden (2. Sam. 22, 34 f.): „Elmacht meine Füsse gleich den Hirschen und stellet mich auf meine Höhe. Er lehret meine Hände streiten und lehret meinen Arm den ehernen Bogen spannen“. Vgl. Ps. 18, 35. In der Völsungasage vermag niemand das Schwert Odins aus dem Eichenstamm herauszuziehen, bis Siegmund naht, dem es ohne Mühe gelingt. Hierher gehört auch der Bogen Janakas im Ramâyana, den Rama allein spannt und zugleich zerbricht. Schon im Mahâbhârata findet sich ähnliches, wenn in einem Gesang Draupadis Hand durch Bogenschuss erworben wird. In einem Fragment des Schöpfungsepos ${ }^{9}$ ) erhebt Anu seinen Bogen, küsst ihn, redet

1) Sam. 2, 3, 35. - 2) 1 Sam. 14, 24. Vgl. auch 1, 31, 13 u. 2, 1, 12. 3) Erman 494, Maspéro, Contes populaires de l'Egypte ancienne. - 4) Grupre, Griech. Mythol. 1. c. u. a. - 5) S. Zeitschr. f. Ethnologie 1895 S. 617. - 6) Herodot III 21. 7) Lepsius, Denhmüler III 65 a. - 8) Zeitschrift f. ägypt. Sprache u. Altertumslacnde 1900 S. $66 .-9)$ K 3449 a Rev, Jensen S. 89. 
ihn an und legt ihm drei Namen bei. Vielleicht lag eine ähnliche Vorstellung wie in den erwähnten Beispielen vor. Doch ist das nur eine Vermutung. Dass zu all jenen obigen Stellen auch babylonische Analoga vorhanden gewesen, ist auch ohnedies wahrscheinlich.

In einer Inschrift Assurbanabals $\left.{ }^{1}\right)^{2}$ ) findet sich Folgendes:

Ich spannte den Bogen, liess entschwirren den Pfeil als Zeichen meiner

Heldenkraft;

ich entsandte, gleich Wurfspiessen, die niederschmetternden Lanzen;

ich ergriff die Zügel n.s. w.

Nach Br. Mersswer") heisst es im Folgenden: „ich lasse die Nabe umdrehen, schiesse, wie kleine Bogen, grosse und gewaltige Bogen." C. F. Lenmaxs, dem ich den Hinweis auf diese Stelle verdanke, macht mich gleichzeitig darauf aufmerksam, dass sich, wie schon Zrмmfrn ${ }^{4}$ ) hervorgehoben hat, auf Assurbanipal mehrfach Mythisches und Eschatologisches angewendet findet. So mag auch diese Stelle in obigen Zulsammenhang einzuordnen sein..$\left.^{5}\right)$

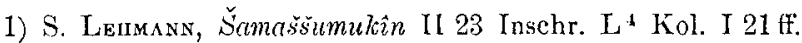

2) P. Jensen bemerkt mir, dass die Stelle Assurbanabal L * Kol. III 10, von der ich obeu S. 168 ausgegangen bin, richtig ubersetzt und ergïnzt, wie folgt, lautet: „Holzscheite wurden entfacht, Fackeln angezindet; auf $1 \mathrm{KAS} . \mathrm{PU}$ ward Helligkeit verbreitet (na-mir-[tul] [s]ak-nat)." C. F. LenManN bestätigt mir dies und schreibt dazu weiter: ${ }_{n}$ So in der Hauptsache schon Deuitzscr, Handwörterbuch Sp. 582 . Tch bedaure, das übersehen und Sie daher nicht darauf aufmerksam gemacht zu baben. Am Sinn wird jedoch kaum etwas verändert. Es handelt sich um lauter Massnahmen, die während der ganzen Dauer der Überführung des Mardukbildes von der Stadt Assur bis nach Babylon fortgesetzt wurden. Wenn dauernd auf eine Wegmeile Helligkeit herrschte, so war zwar natürlich der ganze Umkreis erleuchtet, aber in unserem Zusammenhange kommt es doch wohl zunächst darauf an, dass der Weg des Gottes beleuchtet und durch Feuermale bezeichnet war, deren jedes den Weg ein KAS.PU weit beleuchtete. Entsprechendes wirde gelten, wenn man die Lesung 60 KAS.PU (= dem ganzen Weg (?)) in Betracht zöge, eine Möglichkeit, an die Zimmern erinnert. Wenn etwa, worauf Einiges zu deuten scheint, das Gütterbild auf dem Fluss befördert sein sollte, so sind die übrigen ibm geltenden Massnabmen doch offenbar auf dem Lande vollzogen worden."

3) Zeitschr.f. Ass. X 82. - 4) Bei Schrader, Keilinschriften und altes Testament" S. 382,383 .

5) Zu S. 11 o. ist noch eine Stelle aus einem buddhistischen Gespräch (S. 496 Tr., II 497 Neumann) nachzutragen: „Es streiten Könige mit Königen, Fürsten mit Fürsten, Priester mit Priestern, Bürger mit Burgern, streitet die Mutter mit dem Sohne, der Sohn mit der Mutter, der Vater mit dem Sohne, der Sohn mit dem Vater, streitet Bruder mit Bruder, Bruder mit Scbwester, Schwester mit Bruder, Freund mit Freund." Die Parechese stimmt mit Hesiod und besonders mit den babylonischen Citaten in auffallender Weise überein (S. o. S. 10). Der indische Text beruht, wie auch die merkwürdigen Wiederholungen mit Vertauschung der hochtonigen Worte zeigen, anf einer, wohl brahmanischen, Übersetzung aus dem Babylonischen. 